Check for updates

Cite this: RSC Adv., 2018, 8, 1784

\title{
Novel insensitive energetic-cocrystal-based BTO with good comprehensive properties $\uparrow$
}

\begin{abstract}
Jingjing Tao, ${ }^{a}$ Bo Jin, (D) *a Shijin Chu, ${ }^{a}$ Rufang Peng, ${ }^{* a}$ Yu Shang ${ }^{a}$ and Bisheng $\operatorname{Tan}^{b}$
Combining a layer construction strategy with cocrystallization techniques, we designed and prepared a structurally unusual $1 H, 1^{\prime} H-5,5^{\prime}$-bistetrazole-1, $1^{\prime}$-diolate (BTO) based energetic cocrystal, which we also confirmed by single-crystal $\mathrm{X}$-ray diffraction and powder-crystal $\mathrm{X}$-ray diffraction. The obtained cocrystal crystallizes in a triclinic system, $P-1$ space group, with a density of $1.72 \mathrm{~g} \mathrm{~cm}^{-3}$. The properties including the thermal stability, sensitivity and detonation performance of the cocrystal were analyzed in detail. In addition, the thermal decomposition behavior of the cocrystal was studied by differential calorimetry and thermogravimetry tandem infrared spectroscopy. The results indicated that the cocrystal exhibits strong resistance to thermal decomposition up to $535.6 \mathrm{~K}$. The cocrystal also demonstrates a sensitivity of $>50 \mathrm{~J}$. Moreover, its formation enthalpy was estimated to be $2312.0 \mathrm{~kJ} \mathrm{~mol}^{-1}$, whereas its detonation velocity and detonation pressure were predicted to be $8.213 \mathrm{~km} \mathrm{~s}^{-1}$ and $29.1 \mathrm{GPa}$, respectively, by applying $\mathrm{K}-\mathrm{J}$ equations. Therefore, as expected, the obtained cocrystal shows a good comprehensive performance, which proves that a high degree of layer-by-layer stacking is essential for the structural density, thermal stability and sensitivity.
\end{abstract}

Received 16th October 2017 Accepted 26th December 2017

DOI: 10.1039/c7ra11428a

rsc.li/rsc-advances and cocrystallization to generate compounds with unique properties.

In our design concept, rationally selecting H-bond donoracceptor units is the key to forming a layer-by-layer structure in cocrystal molecule. $1 H, 1^{\prime} H-5,5^{\prime}$-bistetrazole- $1,1^{\prime}$-diolate (BTO) was selected as an $\mathrm{H}$-acceptor group that includes electronegative atoms. This group is a nearly flat building block that features an excellent detonation performance, low production cost, environmental friendliness, and favorable thermal stability. However, the group also displays a comparative density and sensitivity because of the lack of $\mathrm{H}$-bond donor and acceptor units in the crystal structure of some energetic-saltsbased BTO. Therefore, the high crystal packing cannot be achieved, and interlayer sliding is prevented. Additionally, for most energetic compound, there is an inverse relationship between energy density and molecular stability. In the quest for energetic compound with better detonation behavior, there have been reports of $\mathrm{CHON}$-based high explosives. Unfortunately, the majority of them suffer similar problems, for instance, low molecular stabilities, complex synthetic routes and poor resistance to hydrolysis. Since Thomas M. Klapötke reported on BTO salts, numerous ionic salts based on BTO salts have been developed as potential energetic explosives. ${ }^{\mathbf{1 4 - 1 7}}$ Nevertheless, introducing chain cations or cyclic ring cations, including triazole, furazan, and tetrazole, decreases the density and sensitivity of title energetic salts, such as 1,3-diamino-1,2,3triazolium 5,5'-bis(1-oxidotetrazolate) $\left(\rho=1.711 \mathrm{~g} \mathrm{~cm}^{-3}, 2 \mathrm{~J}\right){ }^{18}$ $1 H, 1^{\prime} H$-5, $5^{\prime}$-bistetrazole-1, $1^{\prime}$-diolate $\cdot 2$-(5-amino-2-methyl- $2 H$ tetrazole) $\left(\rho=1.608 \mathrm{~g} \mathrm{~cm}^{-3}, 8 \mathrm{~J}\right){ }^{19}$ and 1,3-diamino-1,2,3-
${ }^{a}$ State Key Laboratory Cultivation Base for Nonmetal Composites and Functional Materials, Southwest University of Science and Technology, Mianyang 621010, China ${ }^{b}$ Institute of Chemical Materials, Chinese Academy of Engineering Physics, Mianyang 621010, China

$\dagger$ CCDC 1487781. For crystallographic data in CIF or other electronic format see DOI: $10.1039 / \mathrm{c} 7 \mathrm{ra} 11428 \mathrm{a}$ 
triazolium nitrotetrazolate-2-oxide $\left(\rho=1.716 \mathrm{~g} \mathrm{~cm}^{-3}, 3 \mathrm{~J}\right){ }^{18}$ Furthermore, density is a major factor affecting explosive performance, which limits the salt's practical application despite a very high nitrogen content reaching $66.7 \%$, and even more importantly, the detonation pressure increases with the square of the density.

Consequently, we considered introducing another $\mathrm{H}_{2} \mathrm{BTO}$ neutral molecule in the imidazolium 5, $5^{\prime}$-bis(1-oxidotetrazolate) (IMBTO) to tune the packing column and increase density via cocrystallization. The assumption was that the IMBTO was chosen as $\mathrm{H}$-bond acceptor, and the $\mathrm{H}_{2} \mathrm{BTO}$ molecule provides both $\mathrm{H}$-bond acceptor and $\mathrm{H}$-bond donor units for pairing. The combination of the IMBTO and $\mathrm{H}_{2}$ BTO molecules was expected to promote increased packing, augmented nitrogen content, enhanced energetic properties, and remarkable sensitivities.

Given the above-mentioned points as guidelines, we present the facile synthesis of a unique energetic cocrystal composed of $\mathrm{H}_{2}$ BTO and IMBTO. As a curious-type energetic cocrystal, the cocrystal was fully characterized through X-ray diffraction and powder X-ray diffraction and proved the feasibility of our strategy. The expected cocrystal imidazolium BTO (CIMBTO) displayed a desirable crystal density of $1.720 \mathrm{~g} \mathrm{~cm}^{-3}$, which is significantly higher than that of the non-cocrystal IMBTO $\left(1.588 \mathrm{~g} \mathrm{~cm}^{-3}\right)$ recently published..$^{20}$ Meanwhile, multinuclear nuclear magnetic resonance (NMR) spectroscopy, infrared (IR) spectroscopy, elemental analysis (EA), differential scanning calorimetry (DSC), and thermogravimetric analysis (TGA) were employed to characterize the prepared cocrystal. The resultant cocrystal also exhibited potentially decent thermal stability, good detonation properties, and extremely low sensitivity toward accidental stimuli; these characteristics highlight the cocrystal's potential energetic application.

\section{Results and discussion}

\section{Synthesis}

$\mathrm{H}_{2}$ BTO was easily prepared in accordance with a previously reported procedure (Scheme 1). ${ }^{19} \mathrm{H}_{2} \mathrm{BTO}$ was then synthesized
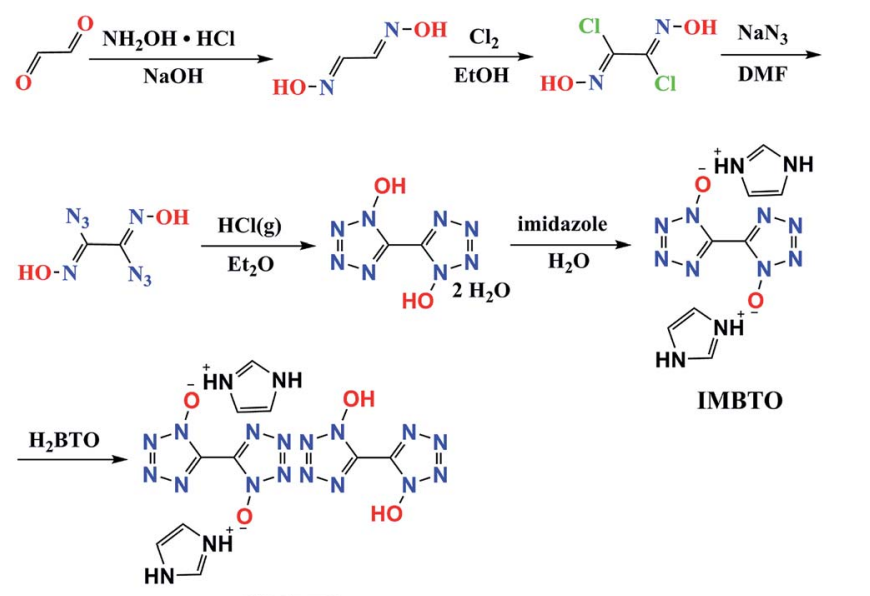

IMBTO from glyoxal, which was treated with hydroxylamine to form glyoxime. Glyoxime was then chlorinated with $\mathrm{Cl}_{2}$ in ethanol. Azido exchange occurred and yielded diazidoglyoxime, which was cyclized under acidic conditions ( $\mathrm{HCl}$ gas in diethyl ether) to produce BTO. The metathesis reaction is analogous to that of non-cocrystal IMBTO. ${ }^{20}$ Thereafter, a cocrystallization experiment was conducted by dissolving the same equivalent of $\mathrm{H}_{2} \mathrm{BTO}$ and IMBTO in a minimum amount of distilled water, and the mixtures were stirred slowly to dissolve. Then, the solution was filtered and the solvent was evaporated over a period of several days at room temperature. A new colorless CIMBTO was then obtained.

\section{Crystal structure}

A high-quality cocrystal was formed by slowly growing from distilled water at room temperature and then assessed by single-crystal X-ray analysis. The results concerning crystallographic data collection and structural refinement are summarized in Table 1, and the molecular moiety of the CIMBTO is displayed in Fig. 1. The selected bond lengths and angles are given in Table 2, and the hydrogen bond lengths and bond angles of CIMBTO are listed in Table 3.

As expected, the test result is consistent with our previous design idea. The developed cocrystal crystallizes in a triclinic system, $P \overline{1}$ space group, with a density of $1.72 \mathrm{~g} \mathrm{~cm}^{-3}$ at $150 \mathrm{~K}$, which is fairly lower than that of $\mathrm{H}_{2}$ BTO $\left(1.811 \mathrm{~g} \mathrm{~cm}^{-3}\right)$ but much superior to that of imidazole $\left(1.030 \mathrm{~g} \mathrm{~cm}^{-3}\right)$. More

Table 1 Crystal data and structural refinement parameters of CIMBTO

\begin{tabular}{|c|c|}
\hline Parameter & CIMBTO \\
\hline Empirical formula & $\mathrm{C}_{10} \mathrm{H}_{12} \mathrm{~N}_{20} \mathrm{O}_{4}$ \\
\hline Formula weight & 476.40 \\
\hline CCDC number & 1487781 \\
\hline Crystal size $\left[\mathrm{mm}^{3}\right]$ & $0.19 \times 0.17 \times 0.16$ \\
\hline Crystal system & Triclinic \\
\hline Space group & $P \overline{1}$ \\
\hline$a[\AA]$ & $3.6752(10)$ \\
\hline$b[\AA]$ & $9.158(2)$ \\
\hline$c[\mathrm{~A}]$ & $13.799(4)$ \\
\hline$\alpha\left[^{\circ}\right]$ & $92.786(3)$ \\
\hline$\beta\left[^{\circ}\right]$ & $97.372(3)$ \\
\hline$\gamma\left[^{\circ}\right]$ & $90.753(3)$ \\
\hline$V\left[\stackrel{\circ}{3}^{3}\right]$ & $460.0(2)$ \\
\hline$Z$ & 1 \\
\hline$\rho_{\text {calcd }}\left[\mathrm{g} \mathrm{cm}^{-3}\right]$ & 1.720 \\
\hline$T[\mathrm{~K}]$ & $150(2)$ \\
\hline$F(000)$ & 244 \\
\hline$R_{\text {int. }}$ & 0.0505 \\
\hline Data & 1616 \\
\hline Restraints & 1 \\
\hline Parameters & 155 \\
\hline $\mathrm{GOF}^{a}$ on $F^{2}$ & 1.046 \\
\hline$R_{1}^{b}(I>2 \sigma(I))$ & 0.0449 \\
\hline$\omega R_{2}(I>2 \sigma(I))$ & 0.1209 \\
\hline$R_{1}$ (all data) & 0.0478 \\
\hline$\omega R_{2}^{c}$ (all data) & 0.1235 \\
\hline
\end{tabular}




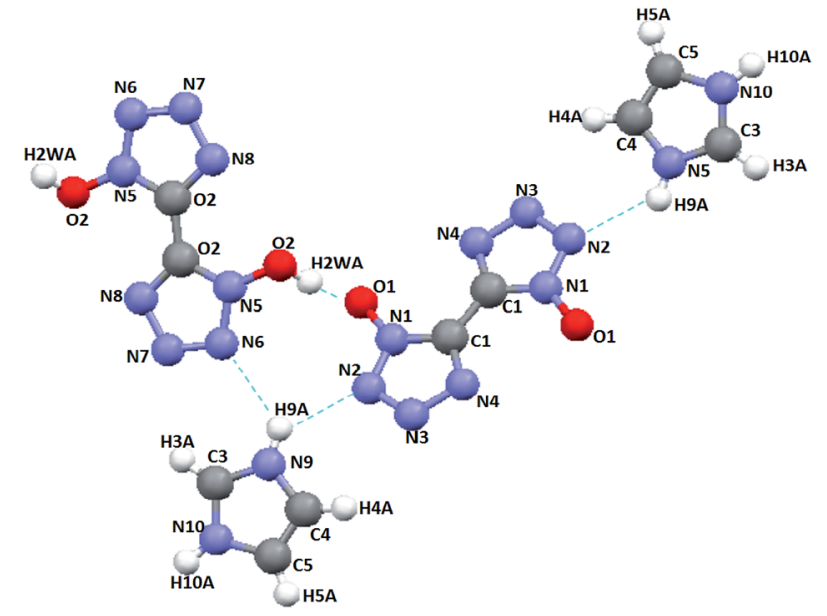

Fig. 1 Molecular structure of CIMBTO.

importantly, the cocrystal is also much superior to the noncocrystal IMBTO $\left(1.588 \mathrm{~g} \mathrm{~cm}^{-3}\right)$ as recently published. ${ }^{20}$ The graphite-like structure of CIMBTO in the solid state was the same as that of the predicted mode and highly contributed to the high density in Fig. 3. By contrast, the favorable density evidently revealed that the cocrystal was certainly a new substance and was partially attributed to the good detonation properties. Additionally, in this work, the energetic cocrystal was formed by combining an energetic salt with a neutral coformer, which is different from many of other cocrystals. It is noted that the imidazole salt of BTO was first prepared, where proton transfer has occurred. Afterward, the salt was cocrystallized with $\mathrm{H}_{2} \mathrm{BTO}$. This would mean that the proton transfer happened before the cocrystallization. Analogously, the similar example can be found in the U.S. patent which present a novel cocrystal composed of HMX and ammonium perchlorate. $^{21}$

Additionally, the phase purity of the cocrystal was verified by performing the powder X-ray diffraction experiment, and then compare it with the simulated data from the SC-XRD. As shown in Fig. 4, the powder X-ray diffraction (PXRD) pattern of the asprepared cocrystal is in agreement with the numerical calculation results converted from the single crystal data, which identifies the cocrystal as a new material with high phase purity. The characteristic peaks are at $9.66^{\circ}, 26.28^{\circ}$, and $28.17^{\circ}$, which can be attributed to the (010), (111) , and (111) respectively. Due

Table 2 Selected bond lengths $[\AA ̊]$ and angles $\left[{ }^{\circ}\right]$ for CIMBTO

\begin{tabular}{llll}
\hline Bond & Length/A & Bond & Angle ${ }^{\circ}$ \\
\hline $\mathrm{N}(1)-\mathrm{N}(2)$ & $1.329(3)$ & $\mathrm{N}(2)-\mathrm{N}(1)-\mathrm{O}(1)$ & $121.94(16)$ \\
$\mathrm{N}(1)-\mathrm{O}(1)$ & $1.331(2)$ & $\mathrm{N}(2)-\mathrm{N}(1)-\mathrm{C}(1)$ & $109.24(16)$ \\
$\mathrm{N}(2)-\mathrm{N}(3)$ & $1.296(3)$ & $\mathrm{N}(3)-\mathrm{N}(2)-\mathrm{N}(1)$ & $106.12(16)$ \\
$\mathrm{N}(3)-\mathrm{N}(4)$ & $1.345(3)$ & $\mathrm{N}(2)-\mathrm{N}(3)-\mathrm{N}(4)$ & $110.94(18)$ \\
$\mathrm{N}(5)-\mathrm{O}(2)$ & $1.327(2)$ & $\mathrm{O}(2)-\mathrm{N}(5)-\mathrm{C}(2)$ & $128.36(17)$ \\
$\mathrm{N}(5)-\mathrm{N}(6)$ & $1.333(3)$ & $\mathrm{C}(2)-\mathrm{N}(5)-\mathrm{N}(6)$ & $109.14(16)$ \\
$\mathrm{N}(6)-\mathrm{N}(7)$ & $1.299(3)$ & $\mathrm{N}(7)-\mathrm{N}(6)-\mathrm{N}(5)$ & $105.93(16)$ \\
$\mathrm{N}(7)-\mathrm{N}(8)$ & $1.342(2)$ & $\mathrm{N}(6)-\mathrm{N}(7)-\mathrm{N}(8)$ & $110.93(18)$
\end{tabular}

Table 3 Hydrogen bond lengths $[\AA \AA]$ and angles $\left[^{\circ}\right]$ for CIMBTO

\begin{tabular}{|c|c|c|c|c|c|}
\hline $\mathrm{D}-\mathrm{H}$ & $d(\mathrm{D}-\mathrm{H})$ & $d(\mathrm{H} \cdots \mathrm{A})$ & $<$ DHA & $d(\mathrm{D} \cdots \mathrm{A})$ & A \\
\hline N9-H9A ${ }^{a}$ & 0.880 & 2.390 & 129.44 & 3.026 & $\mathrm{~N} 2$ \\
\hline N9-H9A ${ }^{a}$ & 0.880 & 2.395 & 131.01 & 3.046 & N6 \\
\hline N10-H10A & 0.880 & 2.241 & 139.21 & 2.964 & N8 \\
\hline $\mathrm{N} 10-\mathrm{H} 10 \mathrm{~A}^{b}$ & 0.880 & 2.436 & 142.63 & 3.180 & $\mathrm{O} 2$ \\
\hline O2-H2WA & 0.873 & 1.555 & 170.12 & 2.420 & O1 \\
\hline $\mathrm{O} 2-\mathrm{H} 2 \mathrm{WA}$ & 0.873 & 2.314 & 155.73 & 3.130 & N1 \\
\hline
\end{tabular}

to the simulated growth conditions and test conditions of the single crystal are different from the experimental one, variance was found to some degree in the intensity.

To verify our assumption further, we studied the packing coefficient, which was calculated as the ratio of the total molecular volume to the unit cell volume, where $73.64 \%$ for CIMBTO was closer to the value for $\mathrm{H}_{2} \mathrm{BTO}$ itself $(74.35 \%)$ and higher than that of IMBTO $(71.53 \%) .{ }^{20}$ This result signifies that the volume and amount of the internal cavities were largely reduced in the cocrystal and that the cocrystal was a new compound.

In the tetrazolate of BTO anion (Table 2), the $\mathrm{N}-\mathrm{N}$ bond lengths varied from 1.296(3) ̊ for N2-N3 to 1.345(3) ̊ for N3$\mathrm{N} 4$. These lengths were between those of the $\mathrm{N}-\mathrm{N}$ single bonds (1.454 $\AA$ ) and $\mathrm{N}=\mathrm{N}$ double bonds $(1.245 \AA) .{ }^{22}$ However, the $\mathrm{C}-\mathrm{C}$ bond connecting the two tetrazole moieties was $1.446 \AA$ long. Such length was located within the normal range of $1.32 \AA$ for the $\mathrm{C}=\mathrm{C}$ bond and $1.53 \AA$ for the $\mathrm{C}-\mathrm{C}$ bond. ${ }^{23}$ Additionally, the $\mathrm{N}-\mathrm{O}$ bonds are found between a $\mathrm{N}-\mathrm{O}$ single bond and a $\mathrm{N}=\mathrm{O}$ double bond $(d(\mathrm{O} 001-\mathrm{N} 001)=1.331(2) \AA) \cdot{ }^{24}$ These observations indicate the existence of a multiple bond and the conjugation of the negative charge throughout the aromatic rings caused by the presence of oxygen atoms. All atoms of the BTO anion were almost coplanar, and the largest torsional angle was $2.58(0.36)^{\circ}$, which was located at O001-N001-C001-C001.

A series of strong intermolecular $\mathrm{N}-\mathrm{H} \cdots \mathrm{N}$ and $\mathrm{O}-\mathrm{H} \cdots \mathrm{O}$ hydrogen bonds formed (Table 3 and Fig. 2). The BTO anion was a $\mathrm{H}$-bond acceptor, and the imidazole cation was a H-bond

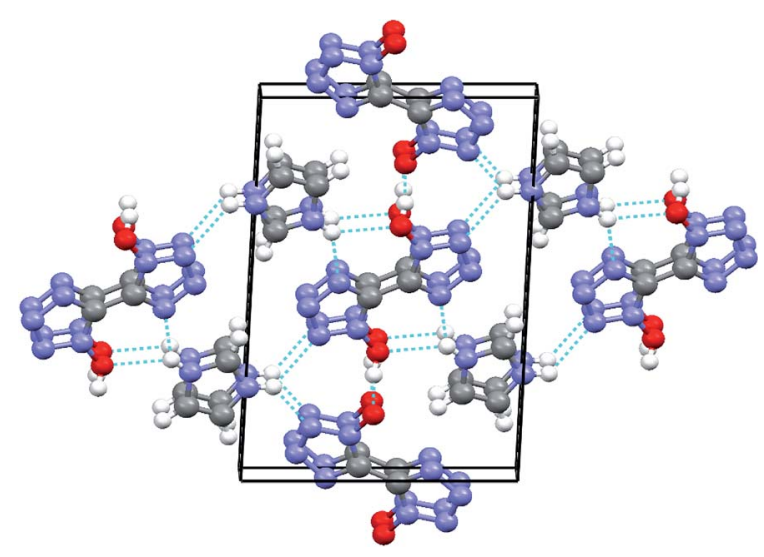

Fig. 2 Packing diagram of CIMBTO along the $a$ axis. 


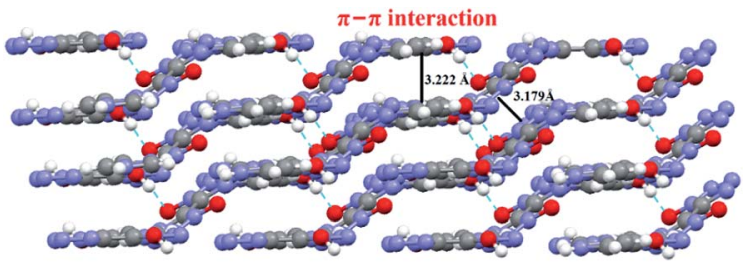

Fig. 3 Packing diagram of CIMBTO along the $b$ axis.

donor. However, the $\mathrm{H}_{2} \mathrm{BTO}$ molecule was a donor and an acceptor of the hydrogen bonds. The packing structure was held not only by electrostatic attraction through cations and anions but also by hydrogen bonds and $\pi-\pi$ interactions. Strong hydrogen bonds were formed in the crystal structure of CIMBTO

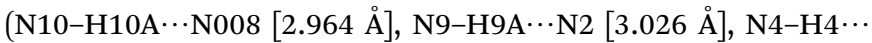
$\mathrm{N} 2[2.433 \AA], \mathrm{N} 10-\mathrm{H} 10 \mathrm{~A} \cdots \mathrm{O} 2$ [3.180 ̊]]) (Fig. 1). Its packing structure of CIMBTO was built and linked to a 2D layer by various hydrogen bonds. Apart from the hydrogen bonds, the $\pi$ stacking interactions were also significant in the cocrystal packing. The structures of CIMBTO and imidazolium BTO salt along the $b$ axis is depicted in Fig. 3. After the layer was assembled, further interlinking of the 2D layers into an intricate 3D supermolecule was stimulated by hydrogen bonding and $\pi$ stacking. Remarkably, these 2D layers in the $b$ axis direction were arranged in a face-to-face arrangement horizontally. As such, the arrangement led to a decent thermal stability and insensitivity.

\section{Spectroscopy}

The structure of CIMBTO was supported further by its corresponding FT-IR, ${ }^{1} \mathrm{H}$ NMR, ${ }^{13} \mathrm{C}$ NMR, and elemental analysis (Experimental section). As shown, in the FT-IR spectrum (Fig. 5), several sharp characteristic bands at 1631, 1425, and $1288 \mathrm{~cm}^{-1}$ were ascribed to the stretching vibration absorption peaks of $\mathrm{C}=\mathrm{N}, \mathrm{N}=\mathrm{N}$, and $\mathrm{N}-\mathrm{O}$, respectively. ${ }^{19}$ The intense broad band at $3410 \mathrm{~cm}^{-1}$ was attributed to the $\mathrm{N}-\mathrm{H}$ stretching vibrations of CIMBTO, and the peak at $3145 \mathrm{~cm}^{-1}$ corresponded

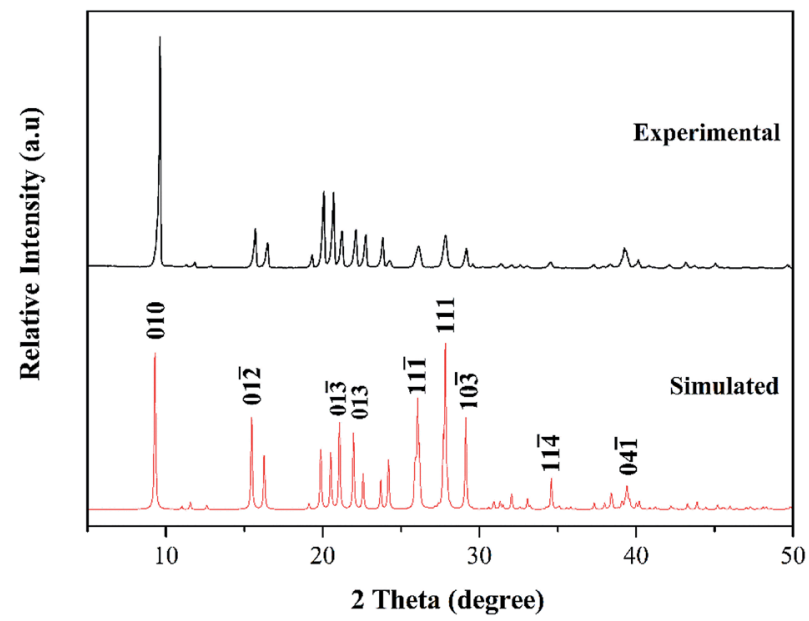

Fig. 4 PXRD patterns of CIMBTO and simulated data from SC-XRD. to the stretching vibrations of $\mathrm{C}-\mathrm{H} .{ }^{25}$ In addition, the peak at $757 \mathrm{~cm}^{-1}$ was caused by the out-plane flexural vibration absorption of $\mathrm{C}-\mathrm{H} .{ }^{25}$ Consequently, the FT-IR spectrum was consistent with the structural features of the compound.

The ${ }^{1} \mathrm{H}$ NMR and ${ }^{13} \mathrm{C}$ NMR spectra also verified the correct structure of CIMBTO. In the ${ }^{1} \mathrm{H}$ NMR spectrum, the signal for the amino group of salt occurred as a broad single band at $\delta /$ $\mathrm{ppm}=9.09 \mathrm{ppm}\left[\mathrm{s}, \mathrm{CH}, \mathrm{NH}^{+}\right]$and $\delta / \mathrm{ppm}=7.70[\mathrm{~s}, \mathrm{CH}=\mathrm{CH}-$ $\left.\mathrm{NH}^{+}\right] .{ }^{25}$ Three signals in the ${ }^{13} \mathrm{C}$ NMR [DMSO-d6] spectrum of the cocrystal were found at $\delta / \mathrm{ppm}=134.86\left[\mathrm{C}=\mathrm{NH}^{+}\right], 119.77$ $\left[\mathrm{CH}-\mathrm{NH}, \mathrm{CH}-\mathrm{NH}^{+}\right]$, and $135.62\left[\mathrm{CN}_{4} \mathrm{O}\right]$, respectively. ${ }^{19,25}$

\section{Energetic performance}

HOF is an important parameter that represents the energy content of an energetic material. Positive values correspond to enhanced detonation properties. The computations were performed with the Gaussian 09 program. ${ }^{26}$

Isodesmic reactions were used to obtain the formation enthalpy of CIMBTO at $298 \mathrm{~K}$. Thus, the empirical KamletJacobs equations ${ }^{27}$ were employed to estimate the values of detonation velocity $(D)$ and detonation pressure $(P)$ for CIMBTO, as shown in the following equations:

$$
\begin{gathered}
D=1.01\left(N \bar{M}^{1 / 2} Q^{1 / 2}\right)^{1 / 2}(1+1.3 \rho) \\
P=1.558 \rho^{2} N \bar{M}^{1 / 2} Q^{1 / 2}
\end{gathered}
$$

where $D$ is the detonation velocity $\left(\mathrm{km} \mathrm{s}^{-1}\right), P$ is the detonation pressure (GPa), $N$ is the explosive detonation that generates gas moles per gram $\left(\mathrm{mol} \mathrm{g}^{-1}\right), \bar{M}$ is the gaseous product of the average molecular weight $\left(\mathrm{g} \mathrm{mol}^{-1}\right), Q$ is the explosive detonation chemical energy per gram $\left(\mathrm{kJ} \mathrm{g}^{-1}\right)$, and $\rho$ is the density ( $\mathrm{g}$ $\mathrm{cm}^{-3}$ ). $Q$ should be calculated before $D$ and $P$ are determined. Moreover, $Q$ is also attained by the $\Delta H_{\mathrm{f}}$ of the detonation reactant and product.

Given the theoretical HOFs and the experimental room temperature density, the detonation properties for IMBTO were predicted by $\mathrm{K}-\mathrm{J}$ equations ${ }^{27}$ (Table 4). CIMBTO showed

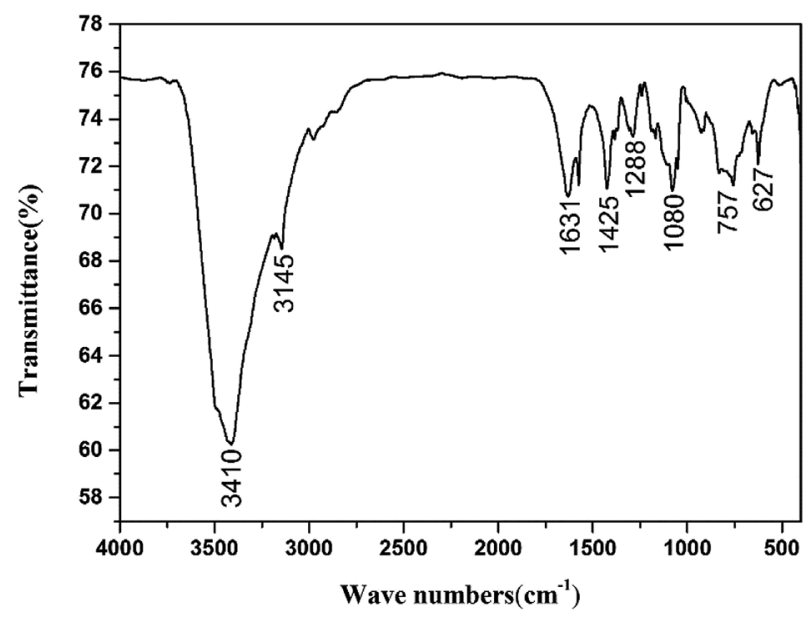

Fig. 5 FT-IR spectrum of CIMBTO. 
Table 4 Properties of CIMBTO compared with IMBTO/TNT/RDX/TATB

\begin{tabular}{|c|c|c|c|c|c|c|c|}
\hline Sample & $T_{\mathrm{dec}^{a}}[\mathrm{~K}]$ & $\rho^{b}\left[\mathrm{~g} \mathrm{~cm}^{-3}\right]$ & $\mathrm{N}+\mathrm{O}^{c}[\%]$ & $\Delta_{\mathrm{f}} H^{d}\left[\mathrm{~kJ} \mathrm{~mol}^{-1}\right]$ & $P^{e}[\mathrm{GPa}]$ & $D^{f}\left[\mathrm{~m} \mathrm{~s}^{-1}\right]$ & $\mathrm{IS}^{g}[\mathrm{~J}]$ \\
\hline CIMBTO & 535.6 & 1.720 & 72.27 & 2312.0 & 29.1 & 8213 & $>50$ \\
\hline IMBTO & 545.9 & 1.588 & 65.36 & 717.6 & 19.0 & 6812 & $>40$ \\
\hline $\mathrm{RDX}^{h}$ & 503.2 & 1.806 & 37.84 & 83.8 & 34.9 & 8748 & 7.5 \\
\hline TATB $^{i}$ & 597.2 & 1.930 & 69.74 & -139.7 & 31.15 & 8114 & 50 \\
\hline
\end{tabular}

${ }^{a}$ Decomposition peak temperature. ${ }^{b}$ Calculated density. ${ }^{c}$ Nitrogen and oxygen content. ${ }^{d}$ Calculated molar formation enthalpy of the salts. ${ }^{e}$ Detonation pressure. ${ }^{f}$ Detonation velocity. ${ }^{g}$ Impact sensitivity. ${ }^{h}$ Ref. $28 .{ }^{i}$ Ref. 29.

a positive HOF of $2312.0 \mathrm{~kJ} \mathrm{~mol}^{-1}$, which was higher than those of HMX (104.8 kJ mol$\left.{ }^{-1}\right)$, TNT (95.3 kJ mol${ }^{-1}$ ), and RDX $\left(83.8 \mathrm{~kJ} \mathrm{~mol}^{-1}\right.$ ) (Table 4$)$.

The performance characteristics are presented in Table 4. As shown, the theoretically computed detonation velocity $(D)$ and detonation pressure $(P)$ were $8213 \mathrm{~m} \mathrm{~s}^{-1}$ and $23 \mathrm{GPa}$, respectively, which were superior to those of TNT. By contrast, the detonation velocity was roughly at the same level as that of RDX, but the cocrystal was more insensitive than the so-called wood explosive TATB. These properties demonstrated that the cocrystal may be used as an insensitive and nitrogen-rich energetic material.

Considering our cocrystal's practical application, the impact sensitivity was determined using a standard BAM Fall hammer apparatus with a $10 \mathrm{~kg}$ drop weight. Fortunately, the attained impact sensitivity of $>50 \mathrm{~J}$ fulfilled our expectations (Table 4). The result shows the low sensitivity of the cocrystal to external stimuli because of a special molecular stacking, including the extensive intermolecular interactions and graphite-like stacking. The majority of explosives, such as TATB, LLM-105, and FOX-7, involve graphite-like stacking, which allows interlayer sliding within a crystal lattice and contributes to low sensitivity. ${ }^{30}$ The cocrystal exhibited a lower sensitivity to external stimuli than those in the traditional energetic materials of RDX (7.4 J), HMX (7 J), and TNT (15 J). ${ }^{31}$

\section{Thermal behavior}

Thermal stability is a crucial factor in energetic materials because an unacceptable thermal stability considerably restricts

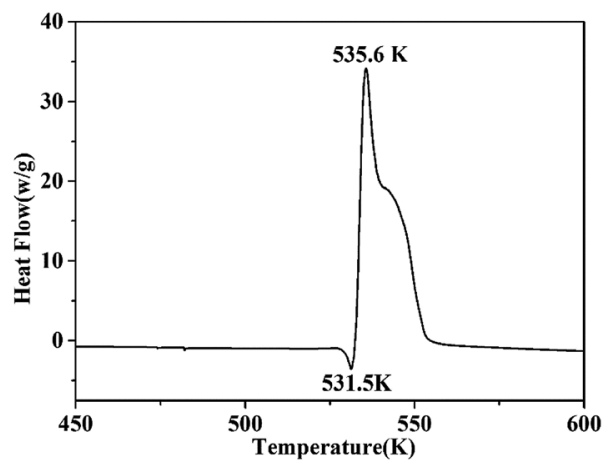

Fig. 6 DSC curve of CIMBTO at the heating rate of $10 \mathrm{~K} \mathrm{~min}^{-1}$. these materials' applications. DSC and TG-DTG were employed with a linear heating rate of $10 \mathrm{~K} \mathrm{~min}^{-1}$ under flowing highpurity nitrogen to determine the thermal decomposition behaviors of the cocrystal. As shown by the DSC curve (Fig. 6), the cocrystal melted at $531.5 \mathrm{~K}$ similar to that in RDX. Such temperature is significantly higher than that of pure $\mathrm{H}_{2}$ BTO $(372.95 \mathrm{~K})$ and implies that the cocrystallization is effective in increasing the melting point of low-melting-point explosives to broaden their applications. ${ }^{32}$ After the melting process was finished, the cocrystal soon exhibited an intense endothermic process with a peak temperature of $535.6 \mathrm{~K}$, which was higher than that of RDX (503.15 K). This temperature level indicates that CIMBTO is a promising energetic material with an excellent thermal stability.

Corresponding to the decomposition processes of the DSC curve, the TG-DTG curves (Fig. 7) show a severe weight loss step of $84.4 \%$ in the range of $509-554 \mathrm{~K}$, and the main exothermic temperature range of CIMBTO was consistent with that of the weight loss. The decomposition behavior of the cocrystal may be explained by the destruction of the crystal structure with rising temperature.

To gain further insight, we also investigated TGA tandem IR spectrum to rapidly identify the constituents of the thermal decomposition gas. Fig. 8 depicts the FT-IR spectra of the thermal decomposition gas during decomposition at their different temperatures. The figure displays that the thermal decomposition of CIMBTO also mainly includes a single stage, which is consistent with the TG-DTG results. The intense

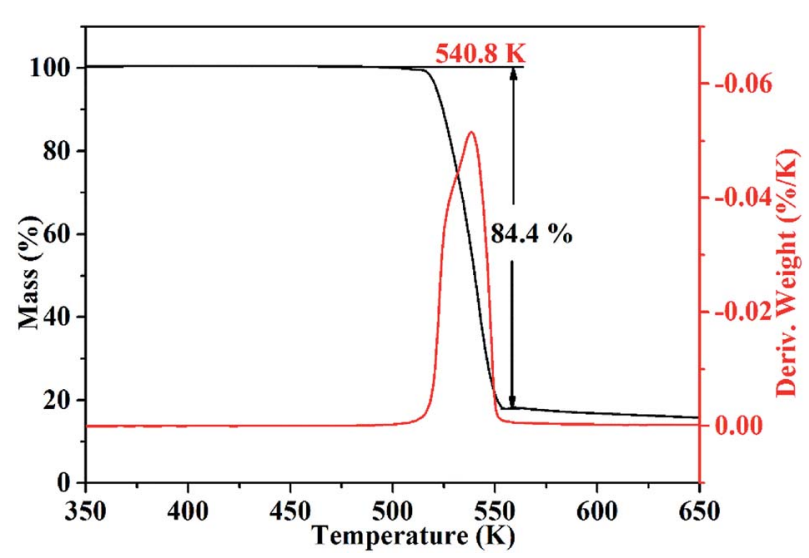

Fig. 7 TG and DTG curves of IMBTO. 


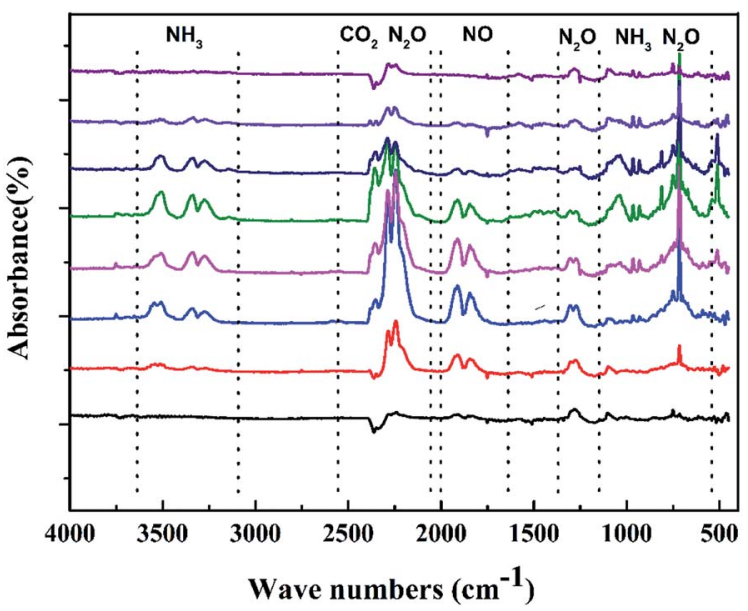

Fig. 8 FT-IR spectra of gas products of CIMBTO during decomposition at individual temperatures.

decomposition occurred at approximately 540.8 K. From Fig. 8, we deduced that the decomposition products were mainly $\mathrm{CO}_{2}$ $\left(2360 \mathrm{~cm}^{-1}\right)$ and $\mathrm{N}_{2} \mathrm{O}\left(2192-2330 \mathrm{~cm}^{-1}\right.$ and $\left.748 \mathrm{~cm}^{-1}\right), \mathrm{NH}_{3}$ (3456, 930, and $\left.965 \mathrm{~cm}^{-1}\right)$, and NO $\left(1786 \mathrm{~cm}^{-1}\right) \cdot{ }^{33,34}$ When the heating temperature was increased to $598.6 \mathrm{~K}$, IR signals nearly disappeared, which proved that CIMBTO was completely decomposed.

\section{Conclusions}

An unusual nitrogen-rich energetic cocrystal was discovered and fully characterized through multinuclear NMR spectroscopy, IR spectroscopy, EA, DSC, and TGA. The structure of CIMBTO was further confirmed through single-crystal X-ray diffraction and powder X-ray diffraction. DSC results revealed that CIMBTO possesses an excellent thermal stability at a decomposition temperature of $535.6 \mathrm{~K}$ and an extremely high melting point of 531.5 K. CIMBTO is insensitive to impact ( $>50 \mathrm{~J}$ ) and can thus be safely handled and applied to specific areas. The superior sensitivity and stability may be explained by the strong hydrogen bond network and graphite-like stacking. Furthermore, the new energetic compound was calculated to yield a detonation pressure of $29.1 \mathrm{GPa}$ and velocity of $8213 \mathrm{~m} \mathrm{~s}^{-1}$. Given its reasonable detonation property, excellent impact sensitivity, and decent stability, CIMBTO can be used as a potential insensitive energetic material for commercial applications.

\section{Experimental section}

\section{Safety precautions!}

Although we experienced no difficulties in the synthesis and characterization of CIMBTO, small-scale syntheses is strongly encouraged. All of the compounds should be handled with extreme care, and eye protection and gloves must be worn at all times.

\section{General methods}

Chemical reagents and solvents were purchased from Aladdin (Shanghai, China) and used as supplied without further purification. ${ }^{1} \mathrm{H}$ NMR and ${ }^{13} \mathrm{C}$ NMR spectra were obtained using a JEOL GSX $600 \mathrm{MHz}$ nuclear magnetic resonance (NMR) spectrometer in a $d^{6}$-DMSO solution by using tetramethylsilane as internal standard. Fourier transform infrared (FT-IR) spectra were recorded on a Nicolet-5700 FTIR spectrometer using pressed $\mathrm{KBr}$ pellets in the wavelength range of $4000 \mathrm{~cm}^{-1}$ to $400 \mathrm{~cm}^{-1}$. Elemental analyses $(\mathrm{C}, \mathrm{H}$, and $\mathrm{N})$ were conducted using a Vario EL CUBE device. DSC was performed by a Q200 DSC instrument (TA Instruments, United States) at a heating rate of $10 \mathrm{~K} \mathrm{~min}^{-1}$ under flowing high-purity nitrogen. TGA was performed with an SDT Q600 TGA instrument (TA Instruments, United States) at a heating rate of $10 \mathrm{~K} \mathrm{~min}^{-1}$ under flowing high-purity nitrogen.

\section{Synthesis of $1 \mathrm{H}, \mathbf{1}^{\prime} \mathrm{H}-5,5^{\prime}$-bistetrazole-1, $\mathbf{1}^{\prime}$-diolate dihydrate (H $\mathrm{H}_{2}$ BTO)}

$1 H, 1^{\prime} H-5,5^{\prime}$-bistetrazole-1, $1^{\prime}$-diolate dihydrate was synthesized according to a procedure reported in the literature. ${ }^{19} \mathrm{H}_{2}$ BTO $\cdot 2 \mathrm{H}_{2} \mathrm{O}$ was synthesized starting from glyoxal, which was treated with hydroxylamine to form glyoxime. Glyoxime was then chlorinated with $\mathrm{Cl}_{2}$ gas in ethanol; chloro/azido exchange occurred to yield diazidoglyoxime, which was cyclized under acidic conditions ( $\mathrm{HCl}$ gas in diethyl ether) to produce $\mathrm{H}_{2} \mathrm{BTO}$.

\section{Synthesis of bis-imidazolium $1 H, 1^{\prime} H-5,5^{\prime}$-bistetrazole-1, $1^{\prime}$ - diolate (IMBTO)}

$1 H, 1^{\prime} H$-5, $5^{\prime}$-bistetrazole-1,1'-diolate dihydrate (206 mg, $1 \mathrm{mmol}$ ) was dissolved in $3 \mathrm{~mL}$ distilled water, and then imidazole (136.2 $\mathrm{mg}, 2 \mathrm{mmol}$ ), previously dissolved in $4 \mathrm{~mL}$ water, was added. The mixture was briefly heated to reflux and filtered. After cooling to room temperature, IMBTO crystallized as colorless needles, yield $233 \mathrm{mg}$ (0.76 mmol, 76\%). IR (KBr) v/ $\mathrm{cm}^{-1}$ : 3468, 3184, 3151, 3085, 1427, 1234, 1163, 1097, 927, 747, 627. ${ }^{1} \mathrm{H}$ NMR $\left(600 \mathrm{MHz},\left[\mathrm{D}_{6}\right] \mathrm{DMSO}, 25{ }^{\circ} \mathrm{C}\right) \delta / \mathrm{ppm}: 8.62,7.37 .{ }^{13} \mathrm{C}$ NMR (150 MHz, [D ${ }_{6}$ DMSO, $\left.25{ }^{\circ} \mathrm{C}\right) \delta / \mathrm{ppm}: 162.17,132.18$, 121.46, 114.55. Elemental analysis (\%) calcd for $\mathrm{C}_{8} \mathrm{H}_{10} \mathrm{~N}_{12} \mathrm{O}_{2}$ (306.20): C, 31.38; H, 3.29; N, 54.88; found: C, 31.30; H, 3.32; N, 54.79 .

\section{Synthesis of the cocrystal CIMBTO}

After confirmed the structure of IMBTO, the same equivalent of $\mathrm{H}_{2}$ BTO (156.56 mg, $0.76 \mathrm{mmol}$ ) and IMBTO (233 mg, $0.76 \mathrm{mmol}$ ) was dissolved in a minimum amount of distilled water, and the mixtures were stirred slowly to dissolve. Then, the solution was filtered and the solvent was evaporated over a period of several days at room temperature. A new colorless CIMBTO was then obtained, yield of $267 \mathrm{mg}$ (0.56 mmol, 74\%). IR (KBr) $v / \mathrm{cm}^{-1}$ : $3410,3145,1631,1574,1425,1288,1169,1080,927,757,627 .{ }^{1} \mathrm{H}$ NMR (600 MHz, $\left.\left[\mathrm{D}_{6}\right] \mathrm{DMSO}, 25{ }^{\circ} \mathrm{C}\right) \delta / \mathrm{ppm}: 9.09,7.70 .{ }^{13} \mathrm{C} \mathrm{NMR}$ (150 MHz, [D 6 DMSO, $25{ }^{\circ} \mathrm{C}$ ) $\delta / \mathrm{ppm}: 135.62,134.86,119.77$. Elemental analysis (\%) calcd for $\mathrm{C}_{8} \mathrm{H}_{10} \mathrm{~N}_{12} \mathrm{O}_{2}$ (306.20): C, 25.22; $\mathrm{H}$, 2.54; N, 58.81; found: C, 25.10; H, 2.56; N, 58.90.

\section{Conflicts of interest}

There are no conflicts to declare. 


\section{Acknowledgements}

This work was supported by the National Natural Science Foundation of China (project no. 51372211) and Open Project of State Key Laboratory Cultivation Base for Nonmetal Composites and Functional (project no. 14tdfk05). Moreover, we also gratefully acknowledge the support of China Academy of Engineering Physics Research Institute of Safety and Ammunition Research and Development Center (project no. RMC2015B01) and the Institute of Chemical Materials, China Academy of Engineering Physics (project no. 16zh0101).

\section{References}

1 D. Fischer, T. M. Klapotke and J. Stierstorfer, Angew. Chem., 2015, 54, 10299-10302.

2 A. A. Dippold and T. M. Klapotke, J. Am. Chem. Soc., 2013, 135, 9931-9938.

3 A. A. Gidaspov, V. V. Bakharev, K. Y. Suponitsky, V. G. Nikitin and A. B. Sheremetev, RSC Adv., 2016, 6, 104325-104329.

4 W. Zhang, J. Zhang, M. Deng, X. Qi, F. Nie and Q. Zhang, Nat. Commun., 2017, 8, 181.

5 J. Zhang, Q. Zhang, T. T. Vo, D. A. Parrish and J. M. Shreeve, J. Am. Chem. Soc., 2015, 137, 1697-1704.

6 J. Zhang, L. A. Mitchell, D. A. Parrish and J. M. Shreeve, J. Am. Chem. Soc., 2015, 137, 10532-10535.

7 Y. Wang, Z. Yang, H. Li, X. Zhou, Q. Zhang, J. Wang and Y. Liu, Propellants, Explos., Pyrotech., 2014, 39, 590-596.

8 Z.-B. Zhang, T. Li, L. Yin, X. Yin and J.-G. Zhang, RSC Adv., 2016, 6, 76075-76083.

9 O. Bolton and A. J. Matzger, Angew. Chem., 2011, 50, 89608963.

10 C. B. Aakeröy and D. J. Salmon, CrystEngComm, 2005, 7, 439.

11 O. Bolton, L. R. Simke, P. F. Pagoria and A. J. Matzger, Cryst. Growth Des., 2012, 12, 4311-4314.

12 J.-T. Wu, J.-G. Zhang, T. Li, Z.-M. Li and T.-L. Zhang, RSC Adv., 2015, 5, 28354-28359.

13 J. Zhang, D. A. Parrish and J. M. Shreeve, Chem. Commun., 2015, 51, 7337-7340.

14 N. Fischer, D. Fischer, T. M. Klapötke, D. G. Piercey and J. Stierstorfer, J. Mater. Chem., 2012, 22, 20418.
15 T. M. Klapötke, P. C. Schmid, S. Schnell and J. Stierstorfer, J. Mater. Chem. A, 2015, 3, 2658-2668.

16 Y. Shang, B. Jin, R. Peng, Z. Guo, Q. Liu, J. Zhao and Q. Zhang, RSC Adv., 2016, 6, 48590-48598.

17 Z. B. Zhang, C. X. Xu, X. Yin and J. G. Zhang, Dalton Trans., 2016, 45, 19045-19052.

18 T. M. Klapötke, D. G. Piercey and J. Stierstorfer, Eur. J. Inorg. Chem., 2013, 2013, 1509-1517.

19 N. Fischer, T. M. Klapötke, M. Reymann and J. Stierstorfer, Eur. J. Inorg. Chem., 2013, 2013, 2167-2180.

20 T. Yang, Z.-B. Zhang and J.-G. Zhang, Z. Anorg. Allg. Chem., 2017, 643, 413-419.

21 U. S. P., 086, 110.

22 D. Fischer, T. M. Klapötke and J. Stierstorfer, Propellants, Explos., Pyrotech., 2012, 37, 156-166.

23 L. Liang, H. Huang, K. Wang, C. Bian, J. Song, L. Ling, F. Zhao and Z. Zhou, J. Mater. Chem., 2012, 22, 10.

24 H. Huang, Z. Zhou, L. Liang, J. Song, K. Wang, D. Cao, C. Bian, W. Sun and M. Xue, Z. Anorg. Allg. Chem., 2012, 638, 392-400.

25 J. Xu, J. Wei, F. Li, Q. Ma and X. Peng, New J. Chem., 2014, 38, 5303-5311.

26 M. Frisch, G. Trucks, H. Schlegel, G. Scuseria, M. Robb, J. Cheeseman, J. Montgomery, J. T. Vreven, K. Kudin and J. Burant, Revision A.02, Gaussian Inc, 2009.

27 H. D. B. Jenkins, H. K. Roobottom, J. Passmore and L. Glasser, Inorg. Chem., 1999, 38, 3609-3620.

28 Y. Tang, H. Gao, D. A. Parrish and J. M. Shreeve, Chemistry, 2015, 21, 11401-11407.

29 H. Gao and J. M. Shreeve, Chem. Rev., 2011, 111, 7377-7436.

30 Y. Ma, A. Zhang, C. Zhang, D. Jiang, Y. Zhu and C. Zhang, Cryst. Growth Des., 2014, 14, 4703-4713.

31 R.-H. Wang, H.-Y. Xu, Y. Guo, R. J. Sa and J. M. Shreeve, J. Am. Chem. Soc., 2010, 132, 11904-11905.

32 C. Guo, H. Zhang, X. Wang, J. Xu, Y. Liu, X. Liu, H. Huang and J. Sun, J. Mol. Struct., 2013, 1048, 267-273.

33 Z. Zhang, G. Wang, N. Luo, M. Huang, M. Jin and Y. Luo, J. Appl. Polym. Sci., 2014, 131, 40965.

34 J. Zhao, B. Jin, R. Peng, N. Deng, W. Gong, Q. Liu and S. Chu, RSC Adv., 2015, 5, 90422-90427. 